\title{
Radiographic Assessment of Unerupted Permanent Maxillary Incisors in Pediatric Patients - A Case Series
}

\author{
Anand $\mathbf{M}^{\mathbf{1}}$, Altaf $\mathrm{G}^{\mathbf{1}}$ and Garg $\mathrm{S}^{\mathbf{2}}$ \\ ${ }^{1}$ Department of Pedodontics and Preventive Dentistry, Sudha Rustagi College of \\ Dental Sciences and Research, Faridabad, Haryana, India \\ ${ }^{2}$ Faculty of Pedodontics and Preventive Dentistry, SGT University, Budhera, \\ Gurgaon, India
}

*Corresponding Author: Altaf G, Department of Pedodontics and Preventive Dentistry, Sudha Rustagi College of Dental Sciences and Research, Faridabad, Haryana, India.
Received: November 29, 2021

Published: December 23, 2021

(C) All rights are reserved by Altaf G., et al.

\begin{abstract}
A completely or partially unerupted maxillary anterior tooth poses an esthetic, psychological and functional concern, especially in children.

Aim: To evaluate the etiology, diagnosis and severity of impaction of permanent maxillary incisors in pediatric patients.

Methodology: Patients in the age group of 8-13 years who presented with completely or partially un-erupted maxillary anterior teeth were selected and evaluated on the basis of etiology and severity.

Result: Thick overlying mucosa and over retained primary teeth are the common etiologies seen in the cases discussed.

Conclusion: Early diagnosis and a prompt treatment can prevent complications. In most cases, Tooth erupts normally if enough space is created in time.
\end{abstract}

Keywords: Unerupted; Maxillary; Incisor; Children; Orthodontic; Over Retained

\section{Background}

An impacted tooth is one which is not able to erupt fully or partially and is positioned in such a way against bone, soft tissue or another tooth, so that its further eruption is impossible. upper anteriors (incisors and canines), often referred to as the 'social six', play an important role in an individual's smile. Delayed eruption of upper incisors requires observation or inter vention when 1) There is emergence of contra lateral teeth that occurred greater than six months previously; when; 2) Eruption of contra lateral teeth that occurred greater than six months previously. 3) Both upper central incisors remain unerupted and the ower incisors have emerged more than one year, previously. 4) deviation from the normal pattern of eruption. Although it is a rare condition but it can have serious impact on esthetics, phonetics, mastication and Psychology in young patients. It can impair development of dental arches and jaw and can lead to major dental problem if left unattended. Various etiological factors are lack of space/malocclusion, narrow arch, habits (Pressure Habits), supernumerary tooth/ odontomas and retained deciduous tooth. 


\section{Case Description}

It is a case series of seven representative cases with different etiology and severity. The patient were selected from cases reported with chief complaint of non - eruption of maxillary incisors in 8- 13 years of age. The severity was assessed on the basis of effect on adjacent teeth, effect on root and root development (Table 1) Cases were taken up from the year January 2017-july 2017 (MALE $=2$, FEMALE $=5$ ).

- CASE 1: 9 year old patient reported with unerupted upper front tooth. Clinically, no eruption bulge was seen (Figure 1a). Radiograph showed no root changes (Figure 1b). Patient presented good oral hygiene. No pathology was associated with oral mucosa.

- CASE 2: 10 year old patient reported with small upper front tooth. On clinical examination, over-retained primary tooth was observed (Figure 2a). No root changes were observed on radiograph (Figure 2b) Fair oral hygiene maintenance was observed and the oral mucosa was clinically healthy.

- CASE 3: 11 year old patient reported with unerupted upper front tooth. Clinically, no eruption bulge was seen (Figure 3a) and on radiographic finding no effect was seen on root development (Figure 3b). Oral hygiene status was good and no mucosal pathology was observed.

- CASE 4: 9 year old patient reported with unerupted upper front teeth. On clinical evaluation over-retained primary tooth was seen (Figure 4a). Radiograph showed no apparent changes (Figure 4b) Sub optimal oral hygiene was observed. Oral mucosa was healthy.

- CASE 5: 10 year old patient reported with unerupted upper front tooth. Clinically, overlying mucosa was observed to be thick and fibrous (Figure 5a). Radiographically, no root changes were seen (Figure 5b). Fair oral hygiene status with no pathological mucosal findings.

- CASE 6: 9 year old patient reported with unerupted upper front tooth. Clinical examination revealed thick fibrous overlying mucosa (Figure 6a). No root changes were observed on radiograph (Figure 6b). Oral hygiene maintenance was satisfactory. No oral mucosal changes were apparent.

- CASE 7: 10 year old patient reported with unerupted upper front tooth. Clinically, thick fibrous overlying mucosa was seen (Figure 7a). Radiographically, no effect was observed on the root (Figure 7b). Oral hygiene presentation was good and no mucosal abnormality was seen.

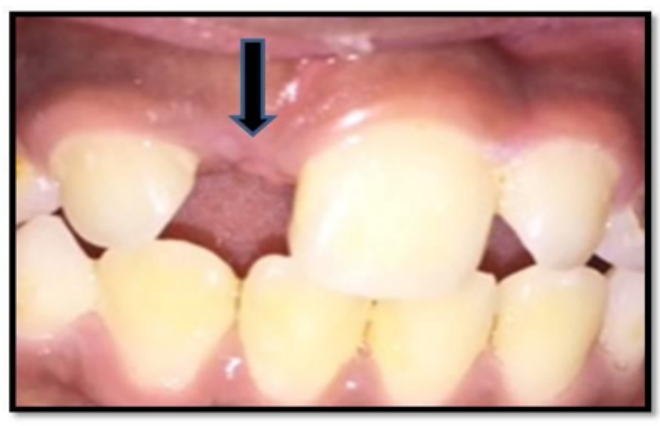

(a)

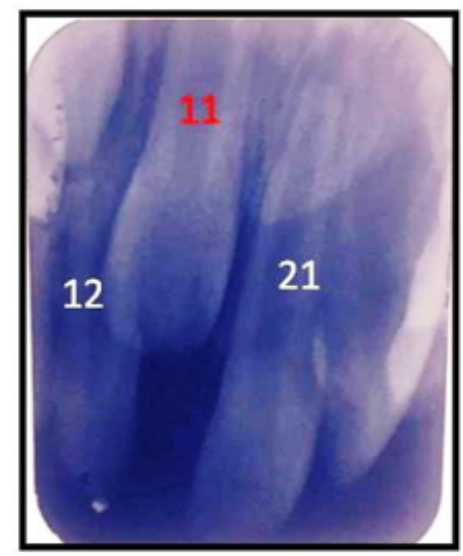

(b)

Figure 1: (a): Case 1 clinically presented no eruption bulge. (b): No root changes observed.

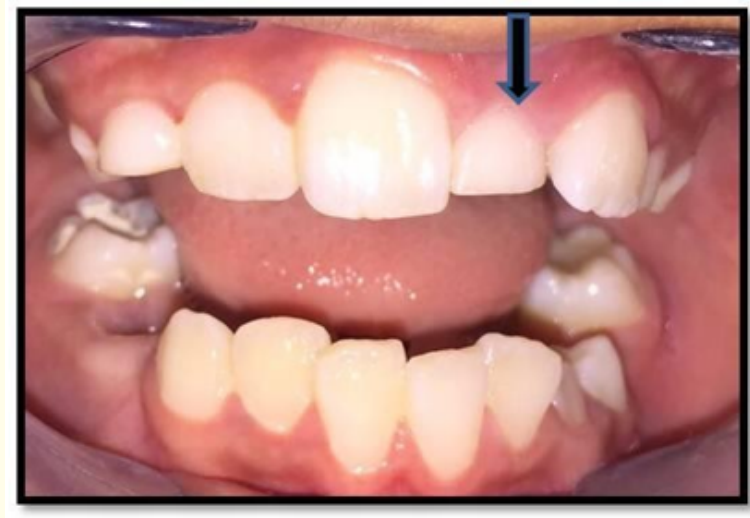

(a) 


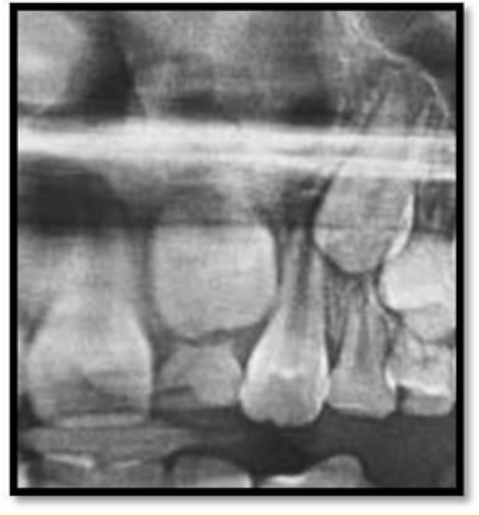

(b)

Figure 2: (a): Case 2 clinically presented over retained primary tooth. (b): No root changes observed.

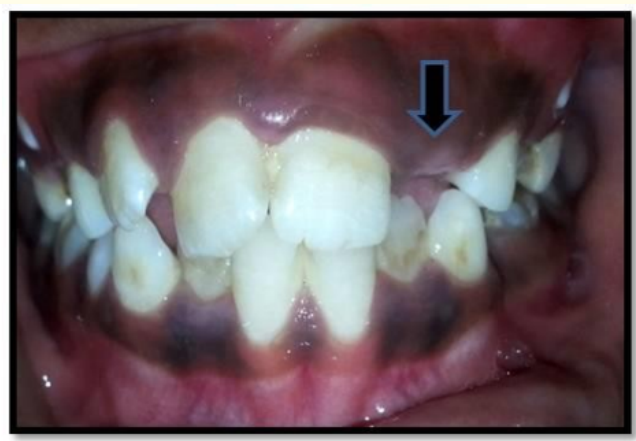

(a)

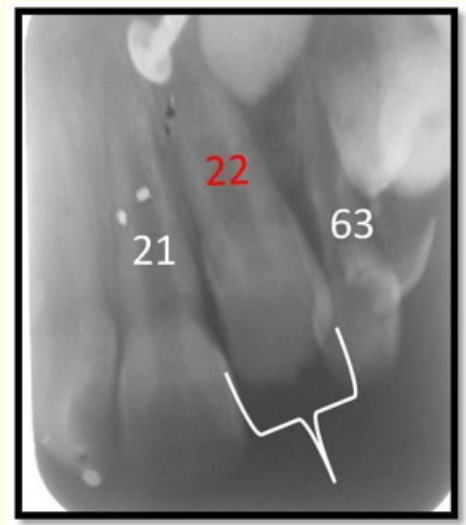

(b)

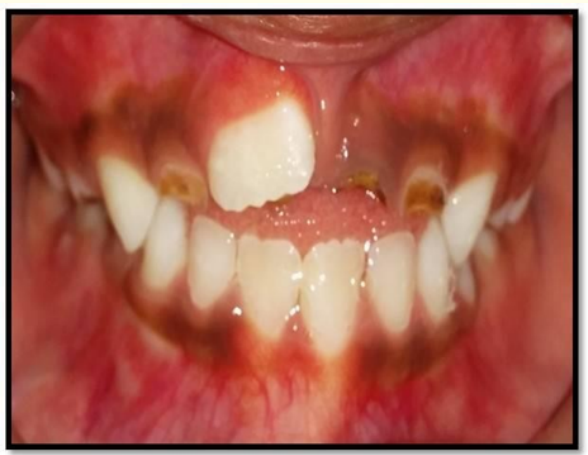

(a)

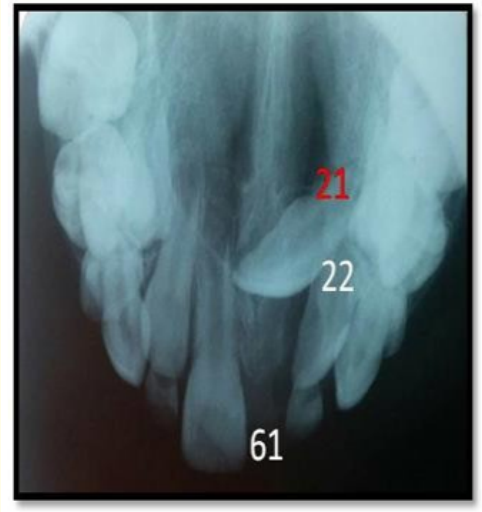

(b)

Figure 4: (a): Case 4 clinically presented over retained primary teeth. (b): No root changes observed.

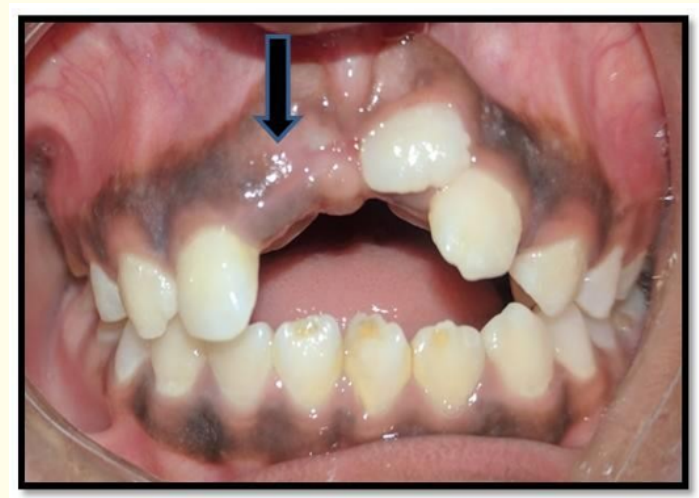

(a)

Figure 3: (a): Case 3 clinically presented no eruption bulge. (b): No root changes observed. 


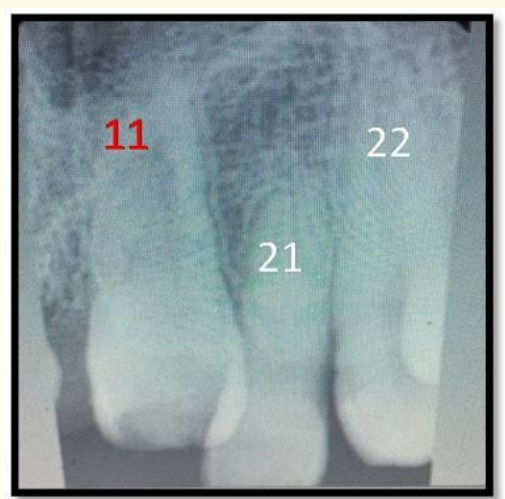

(b)

Figure 5: (a): Case 5 clinically presented thick overlying mucosa. (b): No root changes observed.

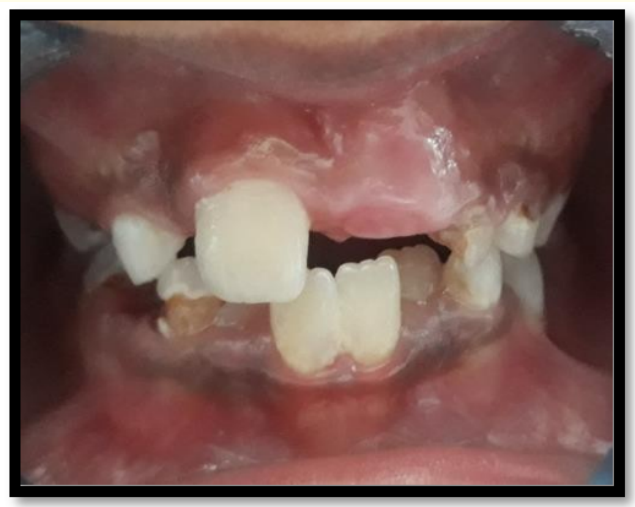

(a)

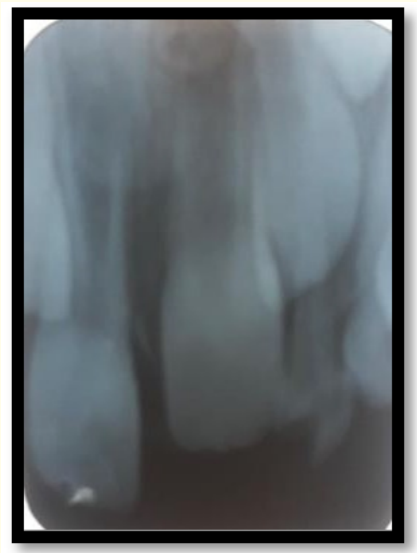

(b)

Figure 6: (a): Case 6 clinically presented thick overlying mucosa. (b): No root changes observed.

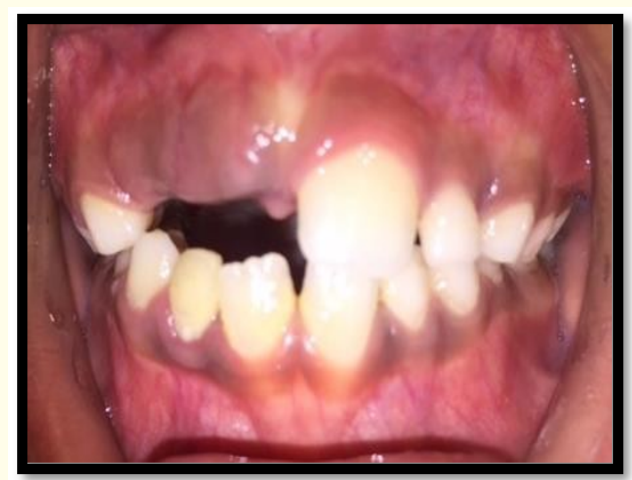

(a)

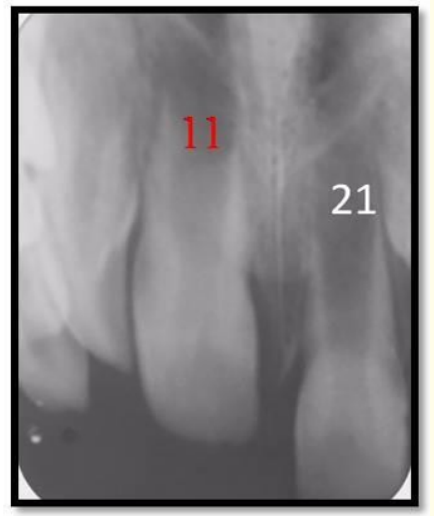

(b)

Figure 7: (a): Case 7 clinically presented thick overlying mucosa. (b): No root changes observed.

Results

Among the seven cases, four right central incisors, two left central incisors and one left lateral incisor were impacted.

Diagnosis in case 1 was made during routine clinical examination. Further investigations revealed insufficient space as the causative factor. Cases 2, 3 and 4 presented a common finding of over retained primary teeth. Thick overlying mucosa was observed in cases 5, 6 and 7. Three cases of unerupted anterior tooth were due to over retained primary tooth and three due to thick overlying mucosa. One case had no apparent etiology.

\section{Management principles}

It is thought that the less time the normal eruption is delayed, the better is the result. If there has been a space loss in the arch, it is im- 


\begin{tabular}{|c|c|c|c|c|c|c|}
\hline & $\begin{array}{c}\text { Tooth } \\
\text { affected }\end{array}$ & $\begin{array}{l}\text { Clinical finding } \\
\text { of non Erupted } \\
\text { tooth }\end{array}$ & $\begin{array}{l}\text { Effect on } \\
\text { adjacent } \\
\text { teeth }\end{array}$ & $\begin{array}{l}\text { Effect on } \\
\text { root }\end{array}$ & Root development & Treatment \\
\hline CASE 1 & 11 & No eruption bulge & No effect & No effect & Incomplete & $\begin{array}{c}\text { Space Regainer and } \\
\text { Interceptive Orthodontic } \\
\text { treatment }\end{array}$ \\
\hline CASE 2 & 21 & $\begin{array}{l}\text { Over retained } \\
\text { primary } \\
\text { tooth }\end{array}$ & No effect & No effect & Incomplete & $\begin{array}{l}\text { Extraction of over retained } \\
\text { primary tooth }\end{array}$ \\
\hline CASE 3 & 22 & $\begin{array}{l}\text { No eruption } \\
\text { bulge }\end{array}$ & No effect & No effect & Incomplete & Operculectomy \\
\hline CASE 4 & 21,22 & $\begin{array}{l}\text { Over retained } \\
\text { primary } \\
\text { tooth }\end{array}$ & No effect & No effect & Incomplete & $\begin{array}{l}\text { Extraction of over retained } \\
\text { primary tooth }\end{array}$ \\
\hline CASE 5 & 11 & $\begin{array}{l}\text { Thick overlying } \\
\text { mucosa }\end{array}$ & No effect & No effect & Incomplete & $\begin{array}{l}\text { Surgical exposure followed } \\
\text { by interceptive orthodontic } \\
\text { treatment }\end{array}$ \\
\hline CASE 6 & 11,21 & $\begin{array}{l}\text { Thick overlying } \\
\text { mucosa }\end{array}$ & No effect & No effect & Incomplete & Operculectomy \\
\hline CASE 7 & 11 & $\begin{array}{c}\text { Thick overlying } \\
\text { mucosa }\end{array}$ & No effect & No effect & Incomplete & Operculectomy \\
\hline
\end{tabular}

Table 1: Summary of Case Findings.

portant to create space before treatment and maintain that space throughout the treatment phase [1]. The treatment options vary from conventional or conservative to more destructive methods $[2]$.

Removal of any barrier would be the most conservative management e.g. in case of retained deciduous tooth or supernumerary tooth extraction of the same is advised for the creation of the space and observe for spontaneous eruption. It has been reported $70 \%$ of teeth erupt spontaneously after removal of barrier, without any further treatment [3].

In some cases, orthodontic extrusion may be required. Various approaches are Presurgical Orthodontics, Exposure and Banding and post-surgical Orthodontics.

Conservative approach is usually implemented if an impacted incisor is associated with a cyst, in order to prevent the loss of the incisor. Marsupialization is the choice of treatment When the conservation of the tooth is preferred in a young patient where the lesion is isolated,. Marsupialization is a method that involves the creation of a surgical window in the wall of the cyst. In Case of thick overlying mucosa remove the soft tissue obstruction [4].

\section{Discussion}

Impaction of upper permanent incisors occur in the mixed dentition and is of great concern to parents and general dentists. Majorly associated with Maxillary central and lateral incisor. Various causative factors responsible are Lack of space, Over-retained primary teeth, Overlying mucosa, Cyst/tumour, Supernumerary teeth. Consequences related are dilacerations, deviated path of eruption, external resorption of adjacent tooth and supra-eruption of opposing tooth [5]. The occurrence of unerupted maxillary incisors can also be associated with hereditary and environmental factors. However, the relevant importance of these different factors is not known. For example, the presence of supernumerary teeth does not necessarily mean that the incisor will be prevented from eruption. 
Present study was planned to evaluate the etiology, diagnosis and severity of partial or complete uneruption of maxillary incisors in 8-13 year old children who reported with the complaint of missing maxillary anterior tooth. The patients were examined clinically and radiographically. The severity was assessed on the basis of effect on adjacent teeth, root and root development.

Eruption failure can also be caused by tooth malformation or dilacerations. Dilacerations occur after trauma to a primary tooth, where the developing permanent tooth bud is damaged due to close proximity to the primary tooth. The degree of damage of the permanent tooth depends on the developmental stage of the tooth as well as the type and direction of the trauma inflicted. Other possible causes of lack of eruption of maxillary incisors are: ectopic position of the tooth bud, non-vital or ankylosed primary teeth, early extraction (or loss) of deciduous teeth, mucosal barriers in the path of eruption that acts as a physical barrier to eruption, endocrine abnormalities, bone diseases [7].

\section{Conclusion}

Disparities in normal eruptive patterns of the upper incisors is not uncommon finding in children but Impaction is rare. Knowledge of the classification, etiology, and treatment modalities for eruption disturbances of the maxillary incisors as well as a thorough examination are needed for an accurate diagnosis, Creation of space and allowing the tooth to erupt alone is usually enough in most cases, however, some may require surgical and/or orthodontic interception. ${ }^{2}$ Each case must be treated individually in order to frame the proper treatment plan and to achieve the best possible outcome for each patient.

\section{Bibliography}

1. Andreasen JO., et al. "The effect of traumatic injuries to primary teeth on their permanent successors. I. A clinical and histological study of 117 injured permanent teeth". Scandinavian Journal of Dental Research 79 (1971): 219-283.

2. Bryan RA., et al. "Retrospective analysis of factors influencing the eruption of delayed permanent incisors after supernumerary tooth removal". European Journal of Paediatric Dentistry 6.2 (2005): 84.

3. Chokron A., et al. "Strategies for treating an impacted maxillary central incisor". International Orthodontics 8.2 (2010): 152-176.
4. Tanki JZ., et al. "Impacted maxillary incisors: causes, diagnosis and management". IOSR Journal of Dental and Medical Sciences (IOSR-JDMS) 5 (2013): 41-45.

5. Pavoni C., et al. "Management of impacted incisors following surgery to remove obstacles to eruption: a prospective clinical trial". Pediatric Dentistry 35.4 (2013): 364-368.

6. Ayers E., et al. "Clinical recommendations for management of mesiodens and unerupted permanent maxillary central incisors". European Archives of Paediatric Dentistry 15.6 (2014): 421-428.

7. Kumar A., et al. "Orthodontic-surgical management of impacted maxillary central incisor". Indian Journal of Orthodontics and Dentofacial Research 3.1 (2017): 56-58.

\section{Assets from publication with us}

- Prompt Acknowledgement after receiving the article

- Thorough Double blinded peer review

- Rapid Publication

- Issue of Publication Certificate

- High visibility of your Published work

Website: www.actascientific.com/

Submit Article: www.actascientific.com/submission.php Email us: editor@actascientific.com

Contact us: +919182824667 